\title{
Short- and long-term efficacy of a community-based COPD management programme in less advanced COPD: a randomised controlled trial
}

\author{
C R van Wetering, ${ }^{1}$ M Hoogendoorn, ${ }^{2}$ S J M Mol, ${ }^{1}$ M P M H Rutten-van Mölken, ${ }^{2}$ \\ A M Schols ${ }^{3}$
}

\section{See Editorial, p 2}

- Additional details are published online only at http:// thorax.bmi.com/content/vol65/ issue 1

${ }^{1}$ Department of Respiratory Medicine, Máxima Medica Centre, Veldhoven, The Netherlands: ${ }^{2}$ institute for Medical Technology Assessment (iMTA), Erasmus MC, Rotterdam, The Netherlands; ${ }^{3}$ Department of Respiratory Medicine, Maastricht University Medical Centre, Maastricht, The Netherlands

Correspondence to: Dr A Schols, Department of Respiratory Medicine, Maastricht University Medical Centre, P 0 Box 5800, 6202 AZ Maastricht, The Netherlands a.schols@pul.unimaas.n

Received 27 April 2009 Accepted 4 August 2009 Published Online First 23 August 2009

\begin{abstract}
Background: The effectiveness of pulmonary rehabilitation in advanced COPD is well established, but few data are available in less advanced disease.

Methods: In a 2 year randomised controlled trial, 199 patients with an average moderate airflow obstruction but impaired exercise capacity (mean (SD) forced expiratory volume in $1 \mathrm{~s}\left(\mathrm{FEV}_{1}\right) 60(16) \%$, peak work load (Wmax) $<70 \%$ ) were randomised to the INTERdisciplinary COMmunity-based COPD management programme (INTERCOM) or usual care. Intervention consisted of 4 months multidisciplinary rehabilitation followed by a 20 month maintenance phase. Outcomes $(4,12$,

24 months): health-related quality of life (St George's Respiratory Questionnaire (SGRQ)), exacerbation frequency, MRC dyspnoea score, cycle endurance time (CET), 6-minute walking distance (6MWD), skeletal muscle strength and patients' and caregivers' perceived effectiveness.
\end{abstract}

Results: Between-group comparison after 4 months revealed the following mean (SE) significant differences in favour of INTERCOM: SGRO total score 4.06 (1.39), $p=0.004$; activity and impact subscores, $p<0.01$; MRC score 0.33 (0.13), $p=0.01$; Wmax 6.0 (2.3) Watt, $\mathrm{p}=0.02$; CET 221 (104) s, $\mathrm{p}=0.04$; 6MWD 13 (6) m, $p=0.02$; hand grip force $4.3(1.5) \mathrm{lb}, p<0.01$; and fatfree mass index $0.34(0.13) \mathrm{kg} / \mathrm{m}^{2}, p=0.01$. Betweengroup differences over 2 years were as follows: SGRO 2.60 (1.3), $p=0.04$; MRC score $0.21(0.10), p=0.048$; CET 253 (104) $\mathrm{s}, \mathrm{p}=0.0156$; 6MWD 18 (8) $\mathrm{m}$, $p=0.0155$. Exacerbation frequency was not different (RR 1.29 (95\% Cl 0.89 to 1.87$))$. Patients' and caregivers' perceived effectiveness significantly favoured the INTERCOM programme $(p<0.01)$.

Conclusions: This study shows that a multidisciplinary community-based disease management programme is also effective in patients with COPD with exercise impairment but less advanced airflow obstruction.

Trial registration number: NCT00840892

In patients with advanced chronic obstructive pulmonary disease (COPD), beneficial effects of pulmonary rehabilitation programmes on exercise capacity, dyspnoea and quality of life are well established. ${ }^{1-3}$ Limited information is available about pulmonary rehabilitation in physically impaired patients with COPD with less advanced disease stages, although the majority of diagnosed patients have mild or moderate COPD as defined by the GOLD guidelines. ${ }^{4-6}$ Until recently, limited attention has been given to exercise intolerance and systemic impairment in patients with earlier stages of the disease. Patients with COPD are markedly inactive, and functional exercise capacity but not forced expiratory volume in $1 \mathrm{~s}\left(\mathrm{FEV}_{1}\right)$ showed the strongest correlation with physical activities in daily life. ${ }^{7}$ A high proportion of patients with muscle atrophy have mild to moderate COPD, independent of body mass index. ${ }^{89}$ No difference was seen in the prevalence of muscle atrophy between moderate and severe COPD. Commonly used GOLD stages do not adequately reflect exercise impairment, systemic impairment and the potential need for pulmonary rehabilitation. In a previous paper we showed that impaired exercise capacity was a significant determinant of disease burden, not only in patients with severe and very severe COPD but also in those with moderate disease..$^{10}$ These findings provided the rationale to study the efficacy of pulmonary rehabilitation in patients with COPD whose exercise capacity is impaired but whose lung function obstruction is less advanced. To be able to provide tailored care to these patients close to their home and to enable access for a large and rapidly growing population of patients with COPD, we designed the INTERdisciplinary COMmunity-based COPD management programme (INTERCOM). The programme consisted of a 4-month rehabilitation phase and a 20-month active maintenance phase. Here we present the results of a 2 year randomised controlled trial evaluating the efficacy of the INTERCOM programme compared with usual care.

\section{METHODS}

\section{Setting and participants}

The INTERCOM trial recruited patients with COPD who were under the supervision of the department of respiratory medicine of two general hospitals in the Netherlands. Patients recruited had (1) impaired exercise capacity, defined as peak work load (Wmax) during incremental cycle ergometry $<70 \%$ of the predicted normal value; (2) GOLD stage 2 or 3 COPD; and (3) were able and willing to participate in a community-based programme. ${ }^{11}$ Patients who had had prior rehabilitation and patients with serious co-morbidity that precluded exercise therapy were excluded Patients were judged to be clinically stable at inclusion by their respiratory physician and pharmacotherapy was optimised.

\section{Randomisation and interventions}

Patients were randomised to the INTERCOM programme or to usual care using a computerised 
procedure with concealed patient allocation. Outcomes were assessed at enrolment and 4, 12 and 24 months after the start of the trial, except for exacerbations which were recorded continuously and peak exercise capacity which was measured at baseline and 4 months only. All measurements were assessed single blind.

\section{INTERCOM programme}

The intervention consisted of an intensive 4-month standardised supervised rehabilitation phase and a 20-month active maintenance phase. The programme was designed to improve and subsequently maintain exercise capacity, to promote selfmanagement skills and improve knowledge of COPD. Nutritional intervention and smoking cessation support were provided when indicated. The programme was offered by local physiotherapists and dieticians in the proximity of the patient's home and by respiratory nurses from the hospital. Local caregivers were supervised by colleagues from the hospital.

During the first 4 months the patients visited the physiotherapists twice a week (30 min per visit) for intensive exercise training consisting of endurance training (cycling and walking) and four specific exercises for upper and lower extremities to improve both strength and endurance without the use of special equipment. Patients were instructed to perform the same exercises twice a day during $30 \mathrm{~min}$ in their home environment in addition to walking and cycling outside. Furthermore, all patients participated in an individualised education programme that was structured using a patient education book. All smokers were assigned to the respiratory nurse for standardised smoking cessation counselling according to the Minimal Intervention Strategy for Lung patients. ${ }^{12}$ Nutritionally depleted patients received scheduled counselling (four visits) by a dietician and nutritional supplements (Respifor, Nutricia, The Netherlands). ${ }^{13}$

During the 20-month active maintenance phase, patients visited the physiotherapist once a month to monitor exercise capacity and adherence to the training and to provide encouragement to continue the exercise training at home. After a patient had experienced an exacerbation, he/she was allowed to start six extra training sessions in 3 weeks at the physiotherapy practice. Nutritionally depleted patients visited the dietician four times in the maintenance phase (after 6, 9, 12 and 24 months). The visits to the respiratory nurse were scheduled upon indication or request.

The usual care group received pharmacotherapy according to accepted guidelines, a short smoking cessation advice by their chest physician and, if they were nutritionally depleted, a recommendation by their respiratory physician to eat more.

\section{Outcomes and follow-up}

Primary outcomes were change from baseline in disease-specific quality of life as assessed by the St George's Respiratory Questionnaire (SGRQ) total score and the total number of exacerbations (moderate plus severe). ${ }^{14}{ }^{15}$ A moderate exacerbation was defined as a visit to the general practitioner or respiratory physician in combination with a prescription of antibiotics and/or prednisolone or a visit to the emergency department or day care of a hospital which, according to the patient, was related to a worsening of COPD symptoms. A severe exacerbation was defined as hospitalisation for a COPD exacerbation.

Secondary outcomes were change from baseline in subscores of the SGRQ (symptom, activity and impact scores), dyspnoea (modified MRC dyspnoea scale), ${ }^{16}$ exercise performance (Wmax), cycle endurance test (CET) at 50\% Wmax for maximal 10 min and thereafter at $70 \%$ Wmax until exhaustion, ${ }^{13}$ 6minute walking test (6MWD), muscle strength (handgrip force (HGF), isometric quadriceps peak torque (OPT), maximal inspiratory mouth pressure (Pimax)), ${ }^{17}$ body composition (fatfree mass (FFM) $)^{18}$ and lung function. Details of the methods are provided in the online supplement.

After 24 months, both patients and caregivers were asked for a global assessment of perceived effectiveness on a 5-point Likert scale (much improved, slightly improved, no change, slightly worse and much worse).

\section{Statistical analyses}

All reported data analyses were prespecified in the statistical analyses plan; $p$ values $<0.05$ indicated statistical significance. The analysis was performed according to an intention-to-treat (ITT) approach. All randomised patients who started the treatment (in the INTERCOM group) and who completed at least one post-randomisation outcome measurement (in both the INTERCOM group and usual care group) were included in the statistical analysis.

Differences in baseline characteristics between patients who completed the trial and patients who prematurely discontinued the trial were statistically tested using independent sample $t$ tests for continuous normally distributed data, Wilcoxon Mann-Whitney $U$ tests for continuous non-normally distributed data and $\chi^{2}$ tests for categorical variables.

Repeated measurement analysis was performed to analyse the change from baseline in all continuous outcome variables using the SAS procedure PROC MIXED with the covariance among repeated measures modelled as "unstructured". The model included treatment, time (ie, measurement at 4, 12 and 24 months), treatment by time interaction, baseline SGRQ score, smoking status at baseline, $\mathrm{FEV}_{1} \%$ predicted at baseline and the self-reported number of exacerbations during the 12 months preceding the trial. Differences in perceived effectiveness were tested using $\chi^{2}$ tests. The total number of exacerbations was compared between treatment groups using negative binomial regression with treatment, smoking status at baseline, $\mathrm{FEV}_{1} \%$ predicted at baseline and the self-reported number of exacerbations during the 12 months preceding the trial as factors and the natural logarithm of the length of the observation period as offset variable. The duration of the exacerbations was subtracted from the length of the observation period.

Based on a mean (SD) SGRQ score of 59 (12.5) and an improvement of 5 units, 98 patients were required in each group $(\alpha=0.05, \beta=0.20)$.

\section{RESULTS}

\section{Patients}

Between January 2002 and December 2004, 199 patients were enrolled in the trial. The patient disposition and the reasons for drop out are shown in fig 1 . The baseline characteristics of the INTERCOM and usual care groups were comparable (table 1). At baseline, 39 patients (20\%) were nutritionally depleted (23 in the INTERCOM group and 16 in the usual care group) and qualified for nutritional intervention. Thirteen of the 199 randomised patients did not start the treatment. The total drop-out rate was $24.5 \%$ (25 patients) in the INTERCOM group and $16.5 \%$ (16 patients) in the usual care group. This difference was not statistically significant $(p=0.22)$. In the INTERCOM 
Figure 1 Patient enrolment scheme. $\mathrm{FEV}_{1}$, forced expiratory volume in $1 \mathrm{~s}$; Wmax, peak work load.

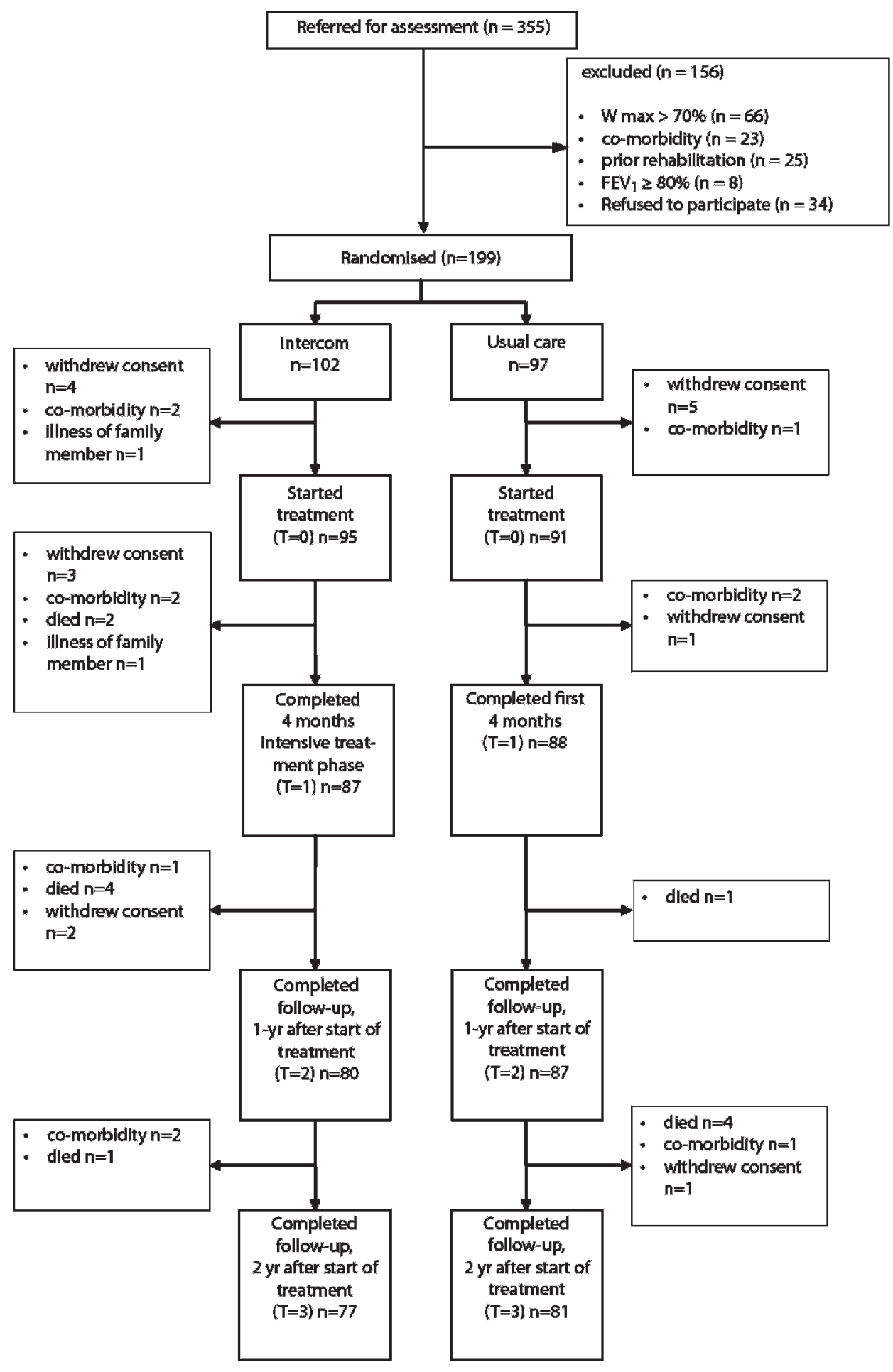

group drop-outs were older than those who completed the study, while in the usual care group drop-outs were younger than those who completed the study.

\section{Outcomes at 4 months}

Primary outcomes

Table 2 shows the results of the 4-month intensive part of the intervention. The SGRO total score improved in the INTERCOM group and remained stable in the usual care group (mean (SE) difference in change from baseline 4.06 (1.39) units $(p=0.004)$. The number of exacerbations after 4 months did not differ between the two groups (RR 1.01 (95\% CI 0.57 to 1.79).

Secondary outcomes

The differences between the two groups in mean (SE) change from baseline in SGRQ activity and SGRQ impact scores were $5.17(2.00)$ units $(p=0.01)$ and $4.26(1.56)$ units $(p=0.007)$, respectively. The between-group difference in mean (SE) change from baseline in MRC score was $0.33(0.13)(p=0.01)$. CET improved by 234 (79) $\mathrm{s}$ in the INTERCOM group compared with 29 (77) $s$ in the usual care group, a mean (SE) difference of 
Table 1 Baseline characteristics of the randomised study population

\begin{tabular}{|c|c|c|}
\hline & \multicolumn{2}{|c|}{ Randomised patients $(n=199$ ) } \\
\hline & INTERCOM $(\mathrm{n}=102)$ & Usual care $(n=97)$ \\
\hline Gender (\% male) & $71 \%$ & $71 \%$ \\
\hline Age (years) & $65.9(8.8)$ & $67.2(8.9)$ \\
\hline Co-morbidities (n) & $1.6(1.6)$ & $1.5(1.4)$ \\
\hline $\begin{array}{l}\text { Exacerbations in } 12 \text { months before } \\
\text { trial }(\mathrm{n})\end{array}$ & $1.2(1.4)$ & $1.0(1.5)$ \\
\hline $\begin{array}{l}\text { COPD hospital admissions in } \\
12 \text { months before trial }(n)\end{array}$ & $0.24(0.52)$ & $0.23(0.50)$ \\
\hline Current smokers (\%) & $33 \%$ & $24 \%$ \\
\hline Smoking (pack-years) & $38.5(25.2)$ & $36.1(26.4)$ \\
\hline $\mathrm{FEV}_{1}(\%$ predicted $)$ & $58(17)$ & $60(15)$ \\
\hline $\mathrm{FEV}_{1} / \mathrm{FVC}(\%)$ & $49(11)$ & $51(12)$ \\
\hline$\%$ patients $\mathrm{FEV}_{1}>50 \%$ predicted & $72 \%$ & $65 \%$ \\
\hline$\%$ patients $\mathrm{FEV}_{1} \leqslant 50 \%$ predicted & $28 \%$ & $35 \%$ \\
\hline SGRO Total score* & $39(15)$ & $38(15)$ \\
\hline SGRO Activity score & $55(18)$ & $56(19)$ \\
\hline SGRO Symptom score & $45(19)$ & $41(22)$ \\
\hline SGRQ Impact score & $27(16)$ & $25(16)$ \\
\hline Total MRC score $\dagger$ & $1.7(1.0)$ & $1.5(0.9)$ \\
\hline 6-min walk test (\% predicted) & $80(13)$ & $83(12)$ \\
\hline Wmax (\% predicted) & $60(19)$ & $61(17)$ \\
\hline HGF (\% predicted) & 77 (17) & $78(18)$ \\
\hline QPT (\% predicted) & $95(21)$ & $92(23)$ \\
\hline Fat-free mass $\left(\mathrm{kg} / \mathrm{m}^{2}\right)$ & $17.1(2.0)$ & $17.6(1.9)$ \\
\hline BMI $\left(\mathrm{kg} / \mathrm{m}^{2}\right)$ & $26.1(4.4)$ & $27.3(4.7)$ \\
\hline
\end{tabular}

Data are $\mathrm{n}(\%)$ or mean (SD).

*St George's Respiratory Questionnaire: a higher score indicates a worse quality of life.

$†$ Modified MRC dyspnoea score.

$\mathrm{BMI}$, body mass index; COPD, chronic obstructive pulmonary disease; FEV ${ }_{1}$, forced expiratory volume in $1 \mathrm{~s}$; FFM, fat-free mass; FVC, forced vital capacity; HGF, handgrip force; 6MWD, 6-minute walking distance; OPT, isometric quadriceps peak torque; SGRO, St George's Respiratory Questionnaire; Wmax, peak exercise capacity.

221 (104) s $(p=0.04)$. Significant differences in favour of the INTERCOM group were also found for the change from baseline in Wmax, walking distance, HGF and FFMI, but not for SGRQ symptom score, OPT, Pimax and BMI (table 2).

\section{Outcomes at 24 months}

Primary outcomes

Figure 2A shows the change over time in SGRQ total score. The SGRQ total score initially improved in the INTERCOM group and remained stable in the usual care group. At 12 months the SGRO score in the INTERCOM group had almost returned to baseline, whereas in the usual care group it remained stable up to 12 months and worsened thereafter. Over the total 2-year period there was a statistically significant difference of 2.60 (1.3) units $(p=0.045)$ in change from baseline between the two groups. The 2-year exacerbation frequency was not significantly different between the groups (RR $1.29 ; 95 \%$ CI 0.89 to 1.87 ).

\section{Secondary outcomes}

Over the 2-year period a significant difference between the groups in change from baseline MRC dyspnoea score of 0.21 (0.10) units $(p=0.048)$ was found in favour of the INTERCOM group (fig $2 \mathrm{~B}$ ). The difference between the INTERCOM group and the usual care group in exercise capacity increased over time. Over 2 years, CET significantly increased in the INTERCOM group by $172(73) \mathrm{s}(\mathrm{p}=0.02)$ and decreased in the usual care group by $81(73) \mathrm{s}(\mathrm{p}=0.27)$, resulting in a mean (SE) difference of 253 (104) s over the 2-year period which was statistically significant ( $p=0.02$, fig $3 \mathrm{~A}$ ). In contrast, functional exercise capacity reflecting habitual walking speed decreased in both groups, but significantly less in the INTERCOM group. The 6MWD score decreased over 24 months in the INTERCOM group by $15.1(5.4) \mathrm{m}(\mathrm{p}<0.01)$ and in the usual care group by $33.4(5.2) \mathrm{m}(\mathrm{p}<0.001)$, resulting in a mean $(\mathrm{SE})$ difference of 18.3 (7.5) s which was statistically significant ( $p=0.016$, fig $3 \mathrm{~B}$ ).

Over the total 2-year period, HGF decreased in the usual care group by $1.9(0.8) \mathrm{lb}(\mathrm{p}=0.02)$ and in the INTERCOM group by $0.08(0.8) \mathrm{lb}(\mathrm{NS})$, resulting in a non-significant mean (SE) difference of $1.8(1.5) \mathrm{lb}(p=0.12)$. Over 2 years, Pimax significantly improved in the INTERCOM group by 0.37 $(0.14) \mathrm{kPa}(p=0.008)$ but did not change in the usual care group (mean (SE) $0.004(0.13) \mathrm{kPa}$ ). This resulted in a mean (SE) difference of $0.37(0.19) \mathrm{kPa}$ over 2 years $(p=0.06)$. BMI in the INTERCOM group significantly increased by $0.31(0.12) \mathrm{kg} / \mathrm{m}^{2}$

Table 2 Outcomes of INTERCOM compared with usual care after 4 months

\begin{tabular}{|c|c|c|c|c|c|}
\hline \multirow[b]{2}{*}{ Health outcome } & \multicolumn{2}{|c|}{ Mean (SE) change from baseline } & \multirow{2}{*}{$\begin{array}{l}\text { Mean (SE) } \\
\text { difference in change } \\
\text { from baseline as } \\
\text { observed }\end{array}$} & \multirow{2}{*}{$\begin{array}{l}\text { Adjusted difference } \\
\text { in change from } \\
\text { baseline* }\end{array}$} & \multirow[b]{2}{*}{ p Value } \\
\hline & $\begin{array}{l}\text { Usual care } \\
(\mathbf{n = 8 8})\end{array}$ & $\begin{array}{l}\text { INTERCOM } \\
(\mathrm{n}=\mathbf{8 7})\end{array}$ & & & \\
\hline SGRO Total & $0.3(1.0)$ & $-3.9(1.1)$ & $4.2(1.5)$ & $4.1(1.4)$ & 0.004 \\
\hline SGRO Activity & $0.9(1.4)$ & $-3.9(1.5)$ & $4.8(2.1)$ & $5.2(2.0)$ & 0.01 \\
\hline SGRO Symptom & $-1.4(1.8)$ & $-3.0(1.9)$ & $1.6(2.6)$ & $1.1(2.3)$ & 0.64 \\
\hline SGRO Impact & $0.5(1.3)$ & $-4.1(1.2)$ & $4.6(1.8)$ & $4.3(1.6)$ & $<0.01$ \\
\hline MRC dyspnoea score & $0.1(0.1)$ & $-0.3(0.1)$ & $0.4(0.1)$ & $0.33(0.13)$ & $<0.01$ \\
\hline CET (s) & $29(77)$ & $234(79)$ & $205(108)$ & $221(104)$ & 0.04 \\
\hline 6MWD (m) & $-15.3(3.9)$ & $-1.4(3.9)$ & $13.8(5.5)$ & $13.3(5.6)$ & 0.02 \\
\hline Wmax (W) & $-0.4(1.7)$ & $5.2(1.6)$ & $5.6(2.3)$ & $6.0(2.3)$ & 0.01 \\
\hline HGF (lb) & $-1.2(1.2)$ & $2.9(1.1)$ & $4.1(1.5)$ & $4.3(1.5)$ & $<0.01$ \\
\hline QPT (Nm) & $2.4(2.3)$ & $-1.0(2.2)$ & $3.4(3.1)$ & $2.1(3.1)$ & 0.51 \\
\hline Pimax (kPa) & $0.06(0.17)$ & $0.23(0.16)$ & $0.16(0.23)$ & $0.27(0.21)$ & 0.21 \\
\hline FFMI $\left(\mathrm{kg} / \mathrm{m}^{2}\right)$ & $-0.23(0.10)$ & $0.15(0.08)$ & $0.38(0.13)$ & $0.34(0.13)$ & 0.01 \\
\hline BMI $\left(\mathrm{kg} / \mathrm{m}^{2}\right)$ & $0.02(0.10)$ & $0.28(0.1)$ & $0.26(0.15)$ & $0.23(0.15)$ & 0.13 \\
\hline $\mathrm{FEV}_{1}(\%$ predicted $)$ & $-1.74(1.04)$ & $0.87(0.72)$ & $2.61(1.27)$ & $2.75(1.28)$ & 0.03 \\
\hline
\end{tabular}

*Difference in change from baseline adjusted for the baseline value of the parameter, smoking status, FEV $_{1}$ percentage predicted and the self-reported number of exacerbations during the 12 months preceding the trial.

$\mathrm{BMI}$, body mass index; $\mathrm{CET}$, cycle endurance test; $\mathrm{FEV}_{1}$, forced expiratory volume in $1 \mathrm{~s}$; FFMI, fat-free mass index; HGF, handgrip force; 6MWD, 6-minute walking distance; OPT, isometric quadriceps peak torque; Pimax, maximal inspiratory mouth pressure; SGRO, St George's Respiratory Questionnaire; Wmax, peak exercise capacity. 
A

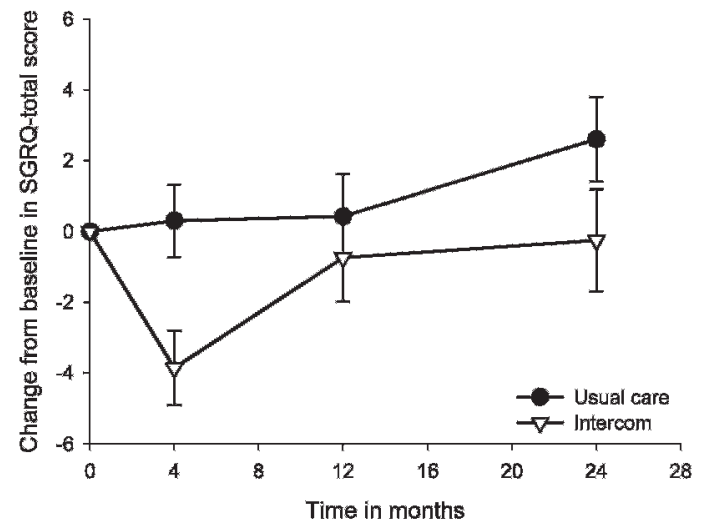

B

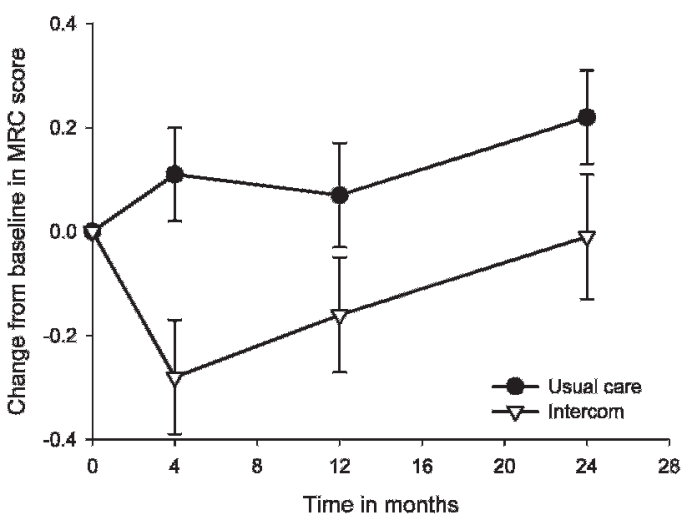

Figure 2 Change from baseline over 24 months in disease-specific quality of life and dyspnoea. (A) St George's Respiratory Questionnaire (SGRQ) total score, $p=0.045$. (B) Medical Research Council (MRC) dyspnoea score, $p=0.048$. INTERCOM, INTERdisciplinary COMmunitybased COPD management programme.

compared with baseline $(p=0.01)$. In the usual care group BMI increased by $0.14(0.12) \mathrm{kg} / \mathrm{m}^{2}(\mathrm{p}=0.24)$, resulting in a nonsignificant mean (SE) difference of $0.18(0.17) \mathrm{kg} / \mathrm{m}^{2}(\mathrm{p}=0.30)$. Over the total 24 months the $\mathrm{FEV}_{1}$ in the usual care group decreased significantly by $2.9(0.7) \%$ predicted $(p<0.001)$. In the INTERCOM group the decrease of $1.6(0.8) \%$ predicted was not significant. The mean (SE) difference between the two groups of $1.3(1.1) \%$ predicted was also not significant. The change from baseline in SGRQ subscores, OPT and FFMI was not significantly different between or within the two groups.

Results on perceived effectiveness showed that, both for patients (fig 4) and respiratory physicians, the perceived effectiveness was significantly better for the INTERCOM group with $p$ values of $<0.001$ and 0.01 , respectively.

\section{DISCUSSION}

To the best of our knowledge, this is the first randomised controlled trial showing that community-based pulmonary rehabilitation is feasible and effective, even for patients with less advanced airflow obstruction. The intensive 4-month rehabilitation resulted in significant improvements in healthrelated quality of life, breathlessness, exercise performance, muscle strength and body composition. In the following 20 months patients participated in an active maintenance programme. Quality of life, functional exercise capacity and breathlessness remained significantly different between the INTERCOM and usual care groups over the entire 2-year
A

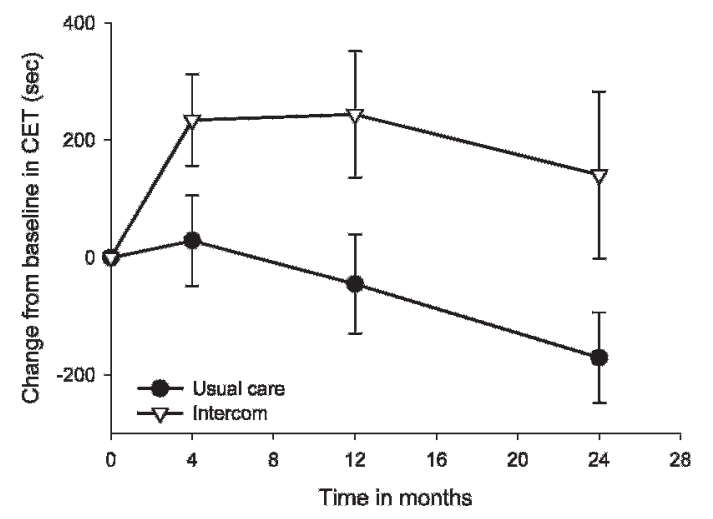

B

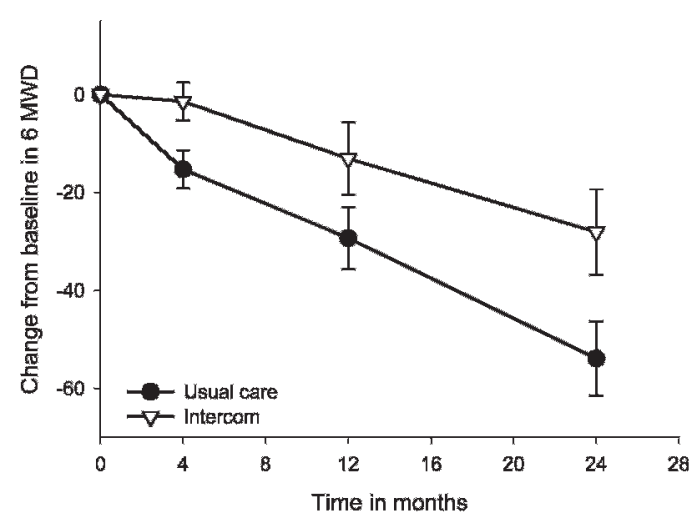

Figure 3 Change from baseline over 24 months in cycle endurance time (CET) and 6-minute walking distance (6MWD). (A) Cycle endurance time, $p=0.020$. (B) Six-minute walking distance, $p=0.016$. Error bars represent standard errors. $p$ Values are based on repeated measurement analysis adjusting for baseline St George's Respiratory Questionnaire (SGRO) score, smoking status, percentage predicted forced expiratory volume in $1 \mathrm{~s}$ and self-reported number of exacerbations during the 12 months preceding the trial. INTERCOM, INTERdisciplinary COMmunity-based COPD management programme.

evaluation. The positive results in terms of functional outcomes were not reflected in a decrease in exacerbation frequency. The influence of pulmonary rehabilitation on exacerbations and their appropriateness as a primary outcome variable is still debated. ${ }^{19}$ Improved early recognition of exacerbations has been suggested to explain a similar or even increased exacerbation frequency after rehabilitation. ${ }^{20} 21$

Community-based pulmonary rehabilitation programmes for patients with COPD have been studied before and significant improvements in exercise capacity, dyspnoea and health-related quality of life have been reported. ${ }^{22-25}$ However, mean percentage predicted $\mathrm{FEV}_{1}$ in former studies was substantially lower at $40-45 \%$ compared with $60 \%$ in our study. Two other Dutch studies have reported the outcome of community-based programmes in patients with COPD with comparable airflow obstruction. ${ }^{2026}$ The COPE study evaluated a COPD selfmanagement programme consisting of fitness, education and self-treatment of exacerbations and reported no significant effect on health-related quality of life and 6MWD after 6 and 12 months. ${ }^{20}$ Campbach et al reported that rehabilitation in local physiotherapy practices improved exercise tolerance and quality of life after 6 months, but the study group consisted of both patients with asthma (35\%) and patients with less severe COPD $(65 \%) .{ }^{26}$ Most of the community-based programmes 
A

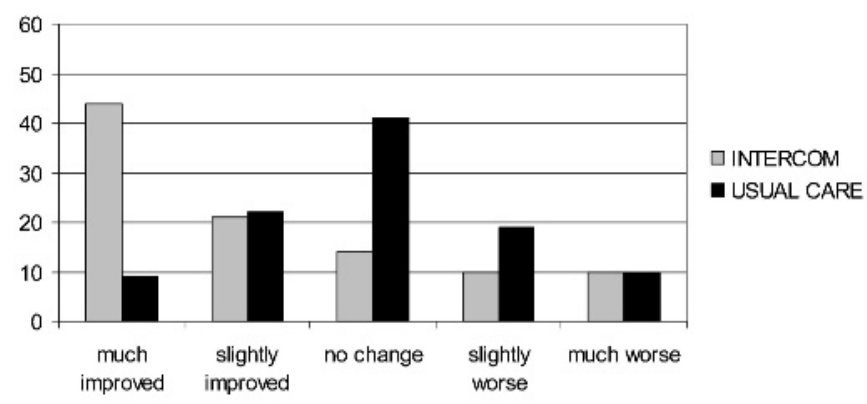

B

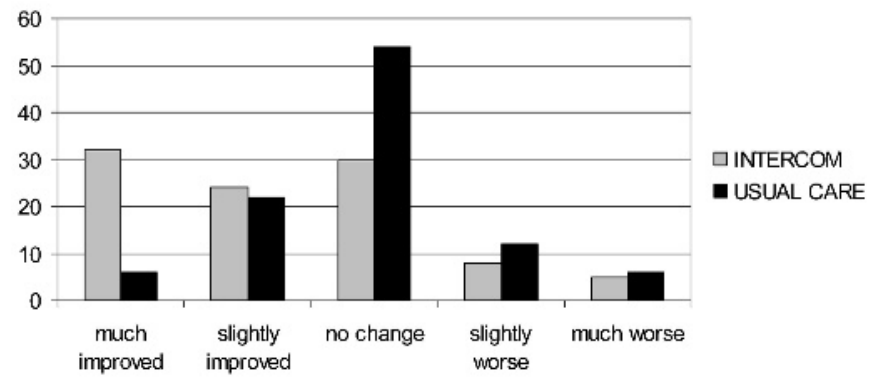

Figure 4 Perceived effectiveness by (A) patients $(p<0.001)$ and (B) chest physicians $(p=0.01)$. INTERCOM, INTERdisciplinary COMmunitybased COPD management programme.

studied previously focused particularly on physical exercise training without providing a comprehensive multidisciplinary approach comparable to the INTERCOM programme..$^{22-26}$ Furthermore, since no data are available on cost-effectiveness of outpatient or home-based pulmonary rehabilitation in patients with less severe COPD, we conducted a full economic evaluation of the INTERCOM programme which is reported elsewhere. ${ }^{27}$

The physiotherapy sessions focused on behavioural changes towards a more physically active lifestyle including walking, cycling, gardening and any form of physical activity tailored to the preferences and possibilities for each individual patient. ${ }^{28}$ This approach has already been proved to be effective in increasing physical activity in healthy elderly subjects but, at the time we designed this study in 2001, had not been applied in COPD before. ${ }^{29} 30$

The within-group change in CET of $278 \mathrm{~s}$ which we observed over 24 months can be considered as clinically relevant according to other studies. ${ }^{31}{ }^{22}$ Recent guidelines advise using a submaximal cycle ergometer test instead of peak exercise capacity as the outcome measure. ${ }^{25}{ }^{33}$ While CET significantly improved after 4 months and was maintained in the active maintenance phase, no improvement was observed in 6MWD. This response pattern may indicate that the $6 \mathrm{MWD}$ is a less sensitive outcome measure of pulmonary rehabilitation programmes, as was indeed recently reported and discussed by Laviolette et al.$^{31} \mathrm{~A}$ remarkable finding was that the 6MWD did not improve in the INTERCOM group. Rather, it declined progressively in both groups, although less so in the INTERCOM group. A potential explanation could be that, in contrast to most other test protocols, we deliberately chose not to encourage patients during the walking test but allowed them to choose their own walking speed. We hypothesise that this observation is indicative of a progressive decline in physical activity pattern. Pitta et al recently quantified physical activities in daily life in healthy control subjects and in patients with COPD with a wide range in disease severity. ${ }^{34}$ Patients were indeed found to have a shorter walking time and lower movement intensity during walking. Interestingly, and in line with our hypothesis, walking time assessed by accelerometry was highly correlated with the 6MWD and more modestly correlated with maximal exercise capacity, lung function and muscle force.

In contrast with the improvements in CET, no effect was seen on quadriceps muscle strength. The lack of effect on this outcome measure is most likely related to the fact that mean quadriceps muscle strength at baseline was within normal limits.

The drop-out rate was $24.5 \%$ in the INTERCOM group, only $19 \%$ of whom actually started the programme. Considering the 2-year duration of the study, this drop-out rate is not unusual. Most patients dropped out because they died or because of serious co-morbidity. It is important to note that only $9 \%$ of the patients in the INTERCOM intervention group dropped out because of unwillingness to continue their participation. This low proportion illustrates the feasibility of the communitybased programme. The drop-out rate in the usual care group was $16.5 \%$. Moreover, while drop-outs in the INTERCOM group were older than those who completed the study, in the usual care group drop-outs were younger. To adjust for potential differences in disease severity between the groups, the statistical analyses were adjusted for baseline SGRO score, smoking status, percentage predicted $\mathrm{FEV}_{1}$ and self-reported number of exacerbations during the 12 months preceding the trial.

In conclusion, our interdisciplinary community-based COPD management programme proved to be a feasible approach to improve disease-specific quality of life, dyspnoea and functional exercise capacity during a 2-year follow-up period in patients with impaired exercise capacity but less advanced airflow obstruction.

Acknowledgements: The authors acknowledge the staff of the Department of Respiratory Medicine, Máxima Medical Centre, Veldhoven and Eindhoven, The Netherlands for their contribution to this trial. They further thank Floortje van Nooten for helping to design and conduct parts of the data collection and data entry.

Funding: This study was financially supported by the Netherlands Asthma Foundation (NAF 3.4.01.63), the "Stichting Astma Bestrijding" (SAB), Nutricia Netherlands, Pfizer and Partners in Care Solutions (PICASSO) for COPD. The funding sources had no role in the design, conduct or reporting of the study or the decision to submit the manuscript for publication.

Competing interests: CRvW has received previous research and travel grants from Nutricia Netherlands. MH and SJMM have no conflicts of interest. MPMHRvM has received previous research grants and speakers fees from Pfizer UK and Pfizer Netherlands and was a board member of the foundation "Stichting Astma Bestrijding" (SAB).

Ethics approval: All patients gave written informed consent for participation in the study. Ethical approval was granted by the Medical Ethics Committee from Máxima Medical Centre.

Provenance and peer review: Not commissioned; externally peer reviewed.

\section{REFERENCES}

1. Troosters T, Gosselink R, Decramer M. Short- and long-term effects of outpatient rehabilitation in patients with chronic obstructive pulmonary disease: a randomized trial. Am J Med 2000;109:207-12.

2. Lacasse $\mathbf{Y}$, Martin S, Lasserson TJ, et al. Meta-analysis of respiratory rehabilitation in chronic obstructive pulmonary disease. A Cochrane systematic review. Eura Medicophys 2007;43:475-85.

3. Guell R, Casan P, Belda J, et al. Long-term effects of outpatient rehabilitation of COPD: a randomized trial. Chest 2000;117:976-83.

4. Nici L, Donner C, Wouters E, et al. American Thoracic Society/European Respiratory Society statement on pulmonary rehabilitation. Am J Respir Crit Care Med 2006;173:1390-413. 
5. Hoogendoorn M, Feenstra TL, Schermer TR, et al. Severity distribution of chronic obstructive pulmonary disease (COPD) in Dutch general practice. Respir Med 2006;100:83-6.

6. Global Initiative for Chronic Obstructive Disease (GOLD). Global strategy for the diagnosis, management and prevention of COPD. 2007. http://www.goldcopd.org.

7. Pitta F, Troosters T, Spruit M, et al. Characteristics of physical activities in daily life in chronic obstructive pulmonary disease. Am J Respir Crit Care Med 2005;171:972-7.

8. Vestbo J, Prescott E, Almdal T, et al. Body mass, fat-free body mass, and prognosis in patients with chronic obstructive pulmonary disease from a random population sample: findings from the Copenhagen City Heart Study. Am J Respir Crit Care Med 2006;173:79-83.

9. Schols AM, Broekhuizen R, Weling-Scheepers CA, et al. Body composition and mortality in chronic obstructive pulmonary disease. Am J Clin Nutr 2005;82:53-9.

10. Van Wetering CR, Van Nooten FE, Mol SJM, et al. Systemic impairment in relation to disease burden in patients with moderate COPD eligible for a lifestyle program. Int J COPD 2008;3:443-51.

11. Jones NL, Makrides L, Hitchcock $C$, et al. Normal standards for an incremental progressive cycle ergometer test. Am Rev Respir Dis 1985;131:700-8.

12. Christenhusz L, Pieterse M, Seydel E, et al. Prospective determinants of smoking cessation in COPD patients within a high intensity or a brief counseling intervention. Patient Educ Couns 2007;66:162-6.

13. Broekhuizen R, Wouters EF, Creutzberg EC, et al. Polyunsaturated fatty acids improve exercise capacity in chronic obstructive pulmonary disease. Thorax 2005:60:376-82.

14. Jones PW, Quirk FH, Baveystock CM, et al. A self-complete measure of health status for chronic airflow limitation. The St. George's Respiratory Questionnaire. Am Rev Respir Dis 1992:145:1321-7.

15. Jones PW. St. George's Respiratory Questionnaire: MCID. COPD 2005;2:75-9.

16. Bestall JC, Paul EA, Garrod R, et al. Usefulness of the Medical Research Council (MRC) dyspnoea scale as a measure of disability in patients with chronic obstructive pulmonary disease. Thorax 1999;54:581-6.

17. Black LF, Hyatt RE. Maximal respiratory pressures: normal values and relationship to age and sex. Am Rev Respir Dis 1969;99:696-702.

18. Schols AM, Wouters EF, Soeters PB, et al. Body composition by bioelectricalimpedance analysis compared with deuterium dilution and skinfold anthropometry in patients with chronic obstructive pulmonary disease. Am J Clin Nutr 1991;53:421-4.

19. Scott CS, Walker P, Calverley PMA. COPD exacerbations. 4: Prevention. Thorax 2006;61:440-7.

20. Monninkhof E, van der Valk $\mathrm{P}$, van der Palen J, et al. Effects of a comprehensive self-management programme in patients with chronic obstructive pulmonary disease. Eur Respir J 2003;22:815-20
21. Wedzicha JA, Seemungal TA. COPD exacerbations: defining their cause and prevention. Lancet 2007;370:786-96.

22. Wijkstra PJ, Strijbos JH, Koeter GH. Home-based rehabilitation for patients with COPD: organization, effects and financial implications. Monaldi Arch Chest Dis 2000;55:130-4.

23. Strijbos JH, Postma DS, van Altena R, et al. A comparison between an outpatient hospital-based pulmonary rehabilitation program and a home-care pulmonary rehabilitation program in patients with COPD. A follow-up of 18 months. Chest 1996:109:366-72.

24. Man WD, Polkey MI, Donaldson N, et al. Community pulmonary rehabilitation after hospitalisation for acute exacerbations of chronic obstructive pulmonary disease: randomised controlled study. BMJ 2004;329:1209.

25. Maltais F, Bourbeau J, Shapiro S, et al. Effects of home-based pulmonary rehabilitation in patients with chronic obstructive pulmonary disease: a randomized trial. Ann Intern Med 2008:149:869-78.

26. Cambach W, Chadwick-Straver RV, Wagenaar RC, et al. The effects of a community-based pulmonary rehabilitation programme on exercise tolerance and quality of life: a randomized controlled trial. Eur Respir J 1997;10:104-13.

27. Hoogendoorn $\mathbf{M}$, van Wetering CR, Schols AM, et al. Is INTERdisciplinary COMmunity-based COPD management (INTERCOM) cost-effective? Eur Respir J 2009 Jul 2 [Epub ahead of print].

28. Donesky-Cuenco D, Janson S, Neuhaus J, et al. Adherence to a home-walking prescription in patients with chronic obstructive pulmonary disease. Heart Lung 2007:36:348-63.

29. Kahn EB, Ramsey LT, Brownson RC, et al. The effectiveness of interventions to increase physical activity. A systematic review. Am J Prev Med 2002;22(4 Suppl):73-107.

30. Dunn AL, Marcus BH, Kampert JB, et al. Comparison of lifestyle and structured interventions to increase physical activity and cardiorespiratory fitness: a randomized trial. JAMA 1999;281:327-34.

31. Laviolette L, Bourbeau J, Bernard S, et al. Assessing the impact of pulmonary rehabilitation on functional status in COPD. Thorax 2008:63:115-21.

32. Casaburi R. Factors determining constant work rate exercise tolerance in COPD and their role in dictating the minimal clinically important difference in response to interventions. COPD 2005;2:131-6

33. Palange $\mathbf{P}$, Ward SA, Carlsen $\mathrm{KH}$, et al. Recommendations on the use of exercise testing in clinical practice. Eur Respir J 2007;29:185-209.

34. Pitta F, Troosters T, Spruit MA, et al. Characteristics of physical activities in daily life in chronic obstructive pulmonary disease. Am Respir Crit Care Med 2005:171:972-7. 